\title{
THE MECHANICAL PROPERTIES OF TRABECULAR BONE: DEPENDENCE ON ANATOMIC LOCATION AND FUNCTION
}

\author{
S. A. GOLDSTEIN \\ Biomechanics, Trauma. and Sports Medicine Laboratory. Section of Orthopaedic Surgery, \\ University of Michigan. Ann Arbor, MI 48109-0486, U.S.A.
}

\begin{abstract}
In 1961, Evans and King documented the mechanical properties of trabecular bone from multiple locations in the proximal human femur. Since this time, many investigators have cataloged the distribution of trabecular bone material properties from multiple locations within the human skeleton to include femur. tibia, humerus, radius, vertebral bodies, and iliac crest. The results of these studies have revealed tremendous variations in material properties and anisotropy. These variations have been attributed to functional remodeling as dictated by Wolff's Law. Both linear and power functions have been found to explain the relationship between trabecular bone density and material properties. Recent studies have re-emphasized the need to accurately quantify trabecular bone architecture proposing several algorithms capable of determining the anisotropy. connectivity and morphology of the bone. These past studies, as well as continuing work. have significantly increased the accuracy of analytical and experimental models investigating bone. and bone implant interfaces as well as enhanced our perspective towards understanding the factors which may influence bone formation or resorption.
\end{abstract}

\section{INTRODUCTION}

Investigating the mechanical properties of trabecular bone and its adaptation to alterations in its physiologic and mechanical environment remains one of the most important arenas in musculoskeletal research. Characterizing its response to metabolic diseases and treatments, fractures, degenerative joint disease, and total joint arthroplasty is inherent to clinical success. Although the physical properties of bone have been investigated for over 100 years, detailed studies on the distribution for trabecular bone material properties have been documented more recently. In 1961, F. Gaynor Evans published a study designed to catalog the regional differences in the physical properties of human trabecular bone from the proximal and distal femoral metaphyses. This study was one of the first to document the tremendous variability of physical properties of trabecular bone. This paper, which was typical of the pioneering work in bone biomechanics published by $\operatorname{Dr}$ Evans, was one of the first to statistically analyze the physical properties of cancellous bone as a function of anatomic location.

The purpose of this paper is to present a review of studies on the physical properties of trabecular bone. The evolution of experiments designed to characterize trabecular bone has moved from material and densitometry studies at a continuum level, to macroscopic propertics of trabecular tissue. Morphologic and

Editor's note. Submitted by editorial invitation for the special ' $F$. Gaynor Evans Anniversary Issue on Bone Biomechanics:. (J. D. Currey, D. R. Carter, A. Viidik. Guest Editors.) architectural observations continue to be made as a means of assessing clinical conditions. Technological advances in both experimental and analytical techniques promise to direct future studies towards more accurate predictions of fracture risks, a detailed understanding of bone's reponse to its mechanical environment, and perhaps elucidating the fundamental mechanisms controlling bone resorption or formation.

\section{COMPRESSIVE PROPERTIES}

Historically, the interest in characterizing the physical properties of trabecular bone centered around the need to evaluate the risk of fracture; epidemiologically recognized to be a consequence of age or metabolic disease. As early as 1876, Rauber determined the specific gravity of fresh specimens of human spongy bone as well as its compressive strengths. More extensive studies of the mechanical behavior of trabecular bone were reported by Gocke $(1925,1928)$, Hardinge (1949), Yokoo (1952), and Knese (1956, 1958).

Evans and King (1961) published one of the first studies designed to investigate the compressive properties of trabecular bone as a function of position within the human femur and loading direction. Their study, which was performed on cubic and rectangular specimens from embalmed femurs, provided the first statistical evidence of the great variation in material properties of trabecular bone as a function of anatomic position. Since this time, many investigators have reported on the mechanical properties of trabecular bone from the major metaphyseal regions of the human body. Perhaps the greatest impetus for these 
studies was the advent of prosthetic joint replacement and the need to understand the bone implant interface.

A summary of published data on the compressive properties of trabecular bone is presented in Table 1. These studies demonstate that trabecular bone acts similarly to porous engineering materials due to its cellular structure and energy absorption capabilities. Its stress/strain response is characterized by a somewhat linear region followed by yield at an extended plastic region maintaining constant stress due to collapse within the cellular framework. As the cellular pores continue to collapse, the stiffness may again increase.

One of the most striking features of this data is the huge variation in modulus and strength reported. These variations have been shown to be a function of anatomic position, loading direction, methods of storage and testing conditions. Some of the most important findings from this large body of work can be summarized as follows:

(1) The most significant and consistent result from these studies was the correlation between the variation in material properties and the function of the bony region tested. These findings support the generally accepted hypothesis that function directly influences the structure and strength of metaphyseal bone, a relationship known as Wolff's Law (Wolfr, 1892).

(2) In general, a linear relationship was found between the elastic modulus and strength of trabecular bone. While the coefficients of this relationship varied among the various authors, the correlations were consistently high.

(3) The strength of the bone was found to be proportional to the strain rate raised to the 0.06 power (Carter and Hayes, 1977) and viscous stiffening due to in situ marrow was only significant at very high strain rates (Carter and Hayes, 1977).

(4) Environmental and testing conditions contributed significantly to the variation of data among the cited studies. Temperature, moisture content and storage conditions are important and make it difficult to compare the absolute values of data from the many laboratories and investigators. Recent work has suggested that preconditioning factors may have also played a major role in measurement stability (Linde and Hvid, 1987).

\section{TENSILE AND SHEAR PROPERTIES}

Compared to the extensive studies on the compressive properties of trabecular bone, only a few studies have attempted to characterize the tensile and shear properties of trabecular bone. Due to its porous, lattice-like structure, the experimental methodologies are demanding and may have contributed to these limited cfforts.

One of the earliest studies was performed by Sonoda in 1962 using trabecular bone from the thoracic and lumbar vertebrae of seven individuals. The results of this study suggested that the tensile strength is significantly less than the compressive strength of trabecular bone. Later studies by Carter et al. (1980) and Neil et al. (1983) in human bone and Bensusan et al. (1983) in bovine trabecular bone. have reported no significant difference between tensile and compressive properties. Finally, in a study by Kaplan et al. (1985) using trabecular bone from fresh bovine humeri, it was demonstrated that the bone was significantly less stiff in tension then in compression and supported an earlier analytical prediction of tensile properties by the same group (Stone et al., 1983).

Shear properties of trabecular bone have also only received limited attention, perhaps due to experimental and conceptual difficulties encountered when testing the highly anisotropic porous structures. Melvin et al. (1970) reported a mean shear strength of approximately $20.7 \mathrm{MPa}$ from cylindrical specimens extracted from human skulls. Halawa et al. (1978) investigated the shear properties of trabecular bone as a function of location within the proximal and distal human femur. Their results demonstrated a range of shear strengths from approximately 1 to $17 \mathrm{MPa}$. The trabecular bone demonstrating the greatest shear strength was found closest to the cortical cancellous junction, but was also dependent on the shear plane chosen relative to the anatomic position of the bone. Saha and Gorman (1981) studying human femoral trabecular bone and Stone et al. (1983) using bovine humeri, found average shear strengths in the range of 5-7 MPa.

\section{REI.ATIONSHIP OF MODULUS AND STRENGTH TO BONE DENSITY}

Although many factors may influence the mechanical properties of trabecular bone, most investigators have attempted to determine the correlation between density measures and the stiffness or strength. The attractiveness of these correlations lies in the fact that these measures are relatively easy and may relate to similar noninvasive techniques enabling the characterization of bone properties to be carried out in vico. Weaver and Chalmers (1966) and Bartley et al. (1966) found positive correlations between human trabecular bone compressive strengths and apparent densities or ash content. Since this time, many studies have documented similar correlations as noted in Table 2. While most investigators demonstrated significant correlations, the unexplained variance and the order of the corresponding relationships between the mechanical properties and the density measures have been quite variable. As noted in Table 2, the relationships have been expressed as a function of linear regressions and power functions.

Current sentiment among investigators tends to favor the power formulations described by Carter and Hayes $(1976,1977)$ due to the similarity of trabecular bone to porous engineering materials. Studies by Patel 
Table 1. A survey of published mechanical properties of human trabecular bone is presented as a function of a natomic location

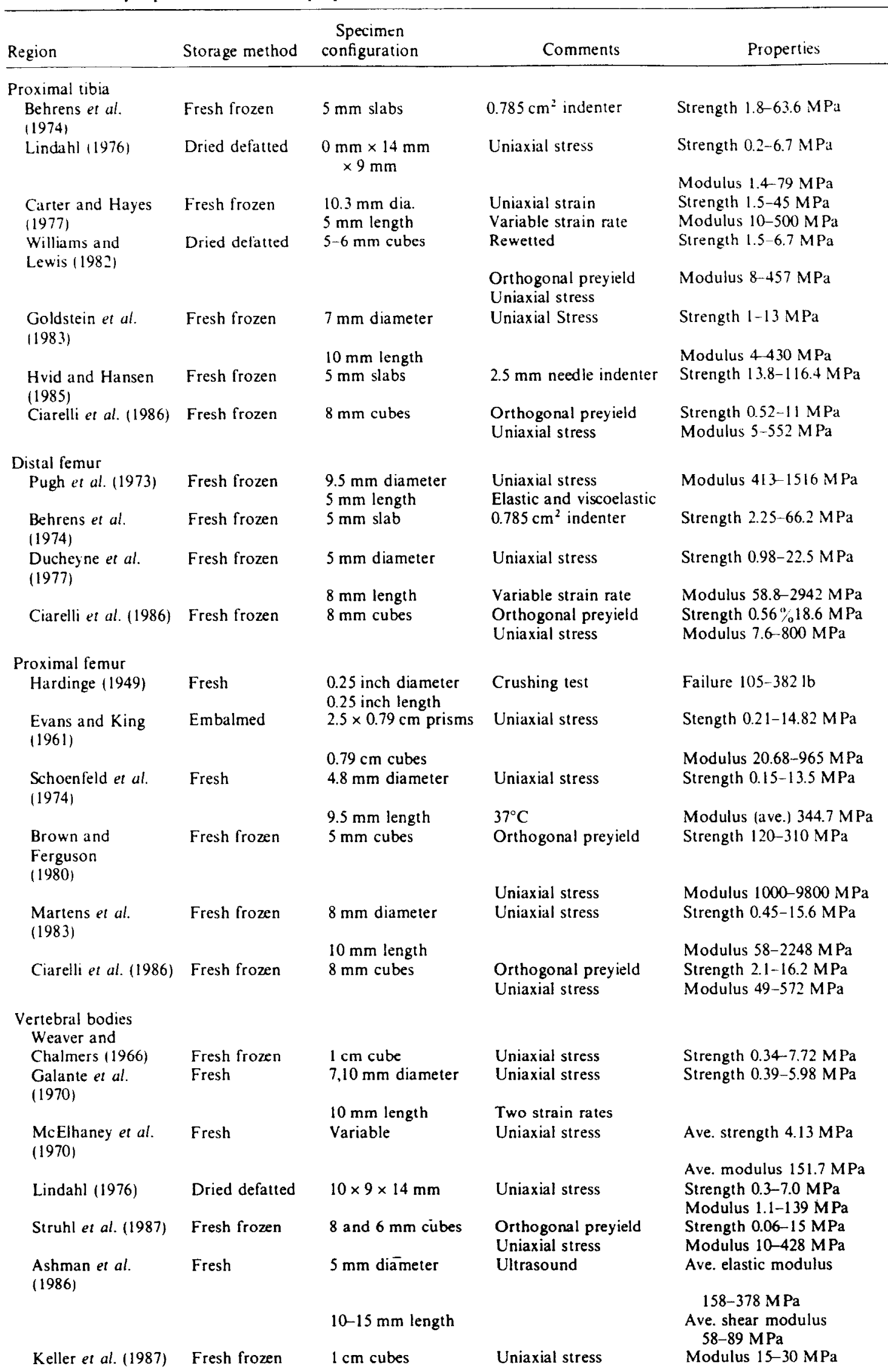


Table 1. (Contd.)

\begin{tabular}{lllll}
\hline Region & Storage method & $\begin{array}{c}\text { Specimen } \\
\text { configuration }\end{array}$ & Comments & Properties \\
\hline $\begin{array}{l}\text { Patella } \\
\text { Townsend } \text { et al. } \\
(1975)\end{array}$ & Fresh & $5.5-10 \mathrm{~mm}$ cubes & Orthogonal moduli & Moduli $121.3-580 \mathrm{MPa}$ \\
$\begin{array}{l}\text { Distal tibia and talus } \\
\text { Hvid and Hansen } \\
\text { (1985) }\end{array}$ & Fresh frozen & $5 \mathrm{~mm}$ slabs & Uniaxial stress & \\
$\begin{array}{l}\text { Calcaneus } \\
\text { Weaver and } \\
\text { Chalmers (1966) }\end{array}$ & Fresh frozen & $1 \mathrm{~cm}$ cubes & Undenter & \\
$\begin{array}{l}\text { Humerus, distal radius } \\
\begin{array}{l}\text { Ciarelli } \text { et al. } \\
\text { (1986) }\end{array}\end{array}$ & Fresh frozen & $8 \mathrm{~mm}$ cubes & Orthogonal preyield & Strength 0.03-6.3 M Pa \\
$\begin{array}{l}\text { Iliac crest } \\
\begin{array}{l}\text { Struhl } \text { et al. } \\
(1987)\end{array}\end{array}$ & Fresh frozen & 6 or $8 \mathrm{~mm}$ cubes & Orthogonal preyield & Strength 0.12-8.2 MPa \\
\hline
\end{tabular}

Table 2

\begin{tabular}{|c|c|c|c|}
\hline Investigators & Region & Relationship & Density measures \\
\hline Weaver and Chalmers (1966) & $\begin{array}{l}\text { Vertebral } \\
\text { Calcaneal }\end{array}$ & Linear & Ash weight \\
\hline Galante et al. (1970) & Vertebral & Linear & $\begin{array}{l}\text { Real density } \\
\text { Apparent density }\end{array}$ \\
\hline McElhaney et al. (1970) & Cranial bone & Power & Apparent density \\
\hline Behrens et al. (1974) & $\begin{array}{l}\text { Distal femur } \\
\text { Proximal tibia }\end{array}$ & Linear & Bulk density \\
\hline Schoenfeld et al. (1974) & Proximal femur & Linear & Apparent density \\
\hline Hayes and Carter (1976) & Bovine distal femur & Power & Apparent density \\
\hline Lindahl (1976) & Vertebral & Linear & Apparent density \\
\hline Carter and Hayes (1977) & Tibial plateau & Power & \\
\hline Ducheyne et al. (1977) & Distal femur & Linear & $\begin{array}{l}\text { Wet and dry } \\
\text { Bulk density }\end{array}$ \\
\hline $\begin{array}{l}\text { Carter et al. (1980) } \\
\text { Martens et al. (1983) }\end{array}$ & $\begin{array}{l}\text { Proximal/distal femur } \\
\text { Proximal femur }\end{array}$ & $\begin{array}{l}\text { Power } \\
\text { Linear }\end{array}$ & $\begin{array}{l}\text { Apparent density } \\
\text { Bulk density } \\
\text { Bone mineral content }\end{array}$ \\
\hline $\begin{array}{l}\text { Stone et al. }(1983) \\
\text { Kaplan et al. }(1985) \\
\text { Ciarelli et al. }(1986)\end{array}$ & $\begin{array}{l}\text { Bovine humeri } \\
\text { Bovine humeri } \\
\text { Distal femur } \\
\text { Proximal femur } \\
\text { Proximal tibia } \\
\text { Proximal humerus } \\
\text { Distal radius }\end{array}$ & $\begin{array}{l}\text { Power } \\
\text { Power } \\
\text { Linear }\end{array}$ & $\begin{array}{l}\text { Apparent density } \\
\text { Apparent density } \\
\text { Apparent density } \\
\text { Ash weight }\end{array}$ \\
\hline
\end{tabular}

The relationship between the mechanical properties and density of trabecular bone have been evaluated in many investigations. Although the order of these correlations varied, each explained significant proportions of the variance in the data.

(1969) in rigid, cellular plastics, Gibson et al. (1981) in cellular materials, and Gibson (1985) in trabecular bone, support the concept of these power relationships relating to deformation patterns in the cellular substructure.

Despite these analytical arguments, the inconsistency in experimental results provides strong evidence of the importance of factors other than density contributing to the mechanical properties of trabecular bone. As with any anisotropic material, the organization of the material components may be more important than the absolute amount of the material present. This obvious dependence of material properties on the architecture of trabecular bone has been noted by virtually all investigators involved in trabecular bone research. The difficulty in characterizing its 
complex, three-dimensional architecture has severely limited the development of algorithms relating this architecture to its subsequent material properties.

\section{ARCHITECTLRAL MEASLRES OF TRABECLLAR BONE}

Most of the earlier work on quantifying the architecture of trabecular bone was summarized in a paper by Hayes and Snyder (1981). Hayes and Snyder, as well as most current investigators, have advanced these earlier techniques through the use of digital analysis algorithms and refined imaging processes.

The emphasis of present investigations is to correlate the influence of morphologic and architectural measures on the material properties of trabecular bone. These correlations are becoming increasingly important as investigators proceed with studies designed to document architectural changes associated with adaptations of bone as a consequence of degenerative joint diseases, total joint arthroplasty, metabolic diseases and treatments, and fractures. It is assumed by most investigators that the architecture of trabecular bone exists as a physiologic optimization maintaining mechanical integrity while minimizing bone mass. Determining the relative contributions of the architectural components to the overall structural properties may provide support for hypotheses relating to the optimization criteria and perhaps the mechanisms fundamental to bone resorption or formation.

Studies by Raux et al. (1975). Pugh et al. (1973), and Townsend et al. (1975) began to investigate the effects of anisotropy, connectivity, as well as morphologic measures (trabecular plate thickness, trabecular plate separation) on the structural properties of trabecular bone. Harrigan and Mann (1984) drawing on the fundamentals of stereology demonstrated that the microstructural anisotropy of orthotropic materials (trabecular bone) could be characterized by a second rank tensor. In subsequent studies, the second rank tensor expression was found to be a good measure of the structural anistropy of trabecular bone and preliminary correlations to elastic properties were formulated (Harrigan and Mann, 1984; Cassidy and Davy, 1985; Cowin, 1985). Predictions of elastic moduli from two-dimensional stereologic techniques (Henshaw et al., 1986) are continuing. In addition, algorithms using morphologic, connectivity and anisotropy measures from three-dimensional digitizations of trabecular bone are also being evaluated (Goldstein et al., 1986).

\section{TRABECLLAR TISSUE PROPERTIES}

As our sophistication in experimental and analytical techniques investigating the physiologic and mechanical behaviour of trabecular bone as a continuum material increases, the properties of trabecular tissue at a microstructural level are becoming increasingly important. Many investigators utilizing structural models to describe the mechanical behavior of trabecular bone assumed that the trabecular tissue possessed the same physical properties as cortical bone (Beaupre and Hayes, 1985; McElhaney, et al., 1970: Pugh et al.. 1973; Tounsend et al.. 1975). Although the predictive accuracy of these models may depend heavily on inclusion of appropriate tissue material properties. few data were available to support or refute this assumption. Townsend et al. (1975) experimentally demonstrated in a buckling study of single human trabeculi, that the modulus of trabecular tissue was very near that of cortical bone. Contradictory evidence has also been reported which suggests that trabecular tissue modulus is considerably less than cortical tissue modulus (Gong et al.. 1964: Williams and Lewis, 1982). Ryan and Williams (1986) reported experimental modulus values an order of magnitude less than cortical tissue. Two recent studies have attempted to address this unresolved subject. Mente and Lewis (1987) described a combined analytical and experimental methodology utilizing irregularly shaped trabeculi to determine the elastic modulus. Ku ct al. (1987) described an experimental protocol utilizing micromachined beams of trabecular bone to determine the mechanical properties of trabecular tissue. Both studies demonstrated a similar range of moduli between 3 and $5 \mathrm{GPa}, 0.20 .5$ the values reported for cortical bone.

\section{SLWMARY}

It is clear that our understanding of the mechanical behavior of trabecular bone significantly increased during the past two decades, paralleling the growth of the field of bone biomechanics and orthopaedic science. The clinical and technological advances in artificial joint replacement both benefited from and inspired the intense effort in characterizing the bone architecturally and mechanically. These past studies, as well as continuing work, have significantly increased the accuracy of analytical and experimental models investigating the effects of metabolic and degenerative diseases and their treatments as well as enhanced our perspective towards understanding the factors which may influence bone formation or resorption.

Many of us are indebted to the pioneering studies of early investigators. I personally have had the great privilege and honor of learning from and working with F. Gaynor Evans, during his tenure at the University of Michigan. It is the dedication, perceptiveness and originality of individuals such as Dr Evans that shape the personality of the investigators and the investigations that follow.

\section{REFERENCES}

Ashman, R. B. Turner, C. II. and Cowin, S. C. (1986) Ultrasonic technique for the measurement of the structural 
elastic modulus of cancellous bone. Transactions of the Orthopedic Research Society, p. 43.

Bartley. M. H. Jr. Arnold. J. S., Haslam, R. K. and Gee. W. S. S. (1966) The relationship of bone strength and bone quantity in health, disease, and aging. J. Geront. 21, 517-521.

Beaupre, G. S. and Hayes, W. C. (1985) Finite element analysis of a three-dimensional open-celled model for trabecular bone. J. biomech. Enyng. 107, 249 256.

Behrens. J. C., Walker, P. S. and Shoji. H. (1974) Variation in strength and structure of cancellous bone at the knee. $J$. Biomechanics 7, 201-207.

Bensusan, J. S., Davy. D. T., Heiple, K. G. and Verdin. P. J. (1983) Tensile, compressive and torsional testing of cancellous bone. Transactions of the Orthopedic Research Society, p. 132.

Brown. T. D. and Ferguson, A. B. (1980) Mechanical property distribution in the cancellous bone of the human proximal femur. Acta orthop. scand. 51, 429-437.

Carter, D. R. and Hayes, W. C. (1976) Bone compressive strength: the influence of density and strain rate. Science 194, 1174-1176.

Carter, D. R. and Hayes, W. C. (1977) The compressive behavior of bone as a two-phase porous structure. J. Bone Jt Surg. 59A, 954-962.

Carter, D. R., Schwab, G. H. and Spengler, D. M. (1980) Tensile fracture of cancellous bone. Acta. orthop. scand. 51, 733-741.

Cassidy, J. J. and Davy, D. T. (1985) Mechanical and architectural properties in bovine cancellous bone. Transactions of the Orthopedic Research Society, p. 354.

Ciarelli, M. J., Goldstein, S. A., Dickie, D., Ku, J. L., Kapper, M., Stanley, J., Flynn, M. J. and Matthews, L. S. (1986) Experimental determination of the orthogonal mechanical properties, density, and distribution of human trabecular bone from the major metaphyseal regions utilizing materials testing and computed tomography. Transactions of the Orthopedic Research Society, p. 42.

Cowin, S. C. (1985) The relationship between the elasticity tensor and the fabric tensor. J. mech. Mat. 4, 137.

Ducheyne, P., Heymans, L., Martens, M., Aernoudt, E., Meester, P. D. and Mulier, J. C. (1977) The mechanical behavior of intracondylar cancellous bone of the femur at different loading rates. J. Biomechanics 10, 747-762.

Evans, F. G. and King, A. L. (1961) Regional differences in some physical properties of human spongy bone. Biomechanical Studies of the Musculo-Skeletal System (Edited by Evans. F. G.) pp.49-67. C. C. Thomas, Springfield, IL.

Galante, J., Rostoker, W. and Ray, R. D. (1970) Physical properties of trabecular bone. Calcif. Tissue Res. 5, 236-246.

Gibson, L. J., Easterling, K. E. and Ashby, M. F. (1981) The structure and mechanics of cork. Proc. R. Soc. Lond., A377, 99-117.

Gibson. L. J. (1985) The mechanical behavior of cancellous bone. J. Biomechanics 18, 317-328. Gocke. C. (1925) Das Verhalten Spongiosen Knochens im Druck-und Schlagversuch. Z. Orthop. Chir. 47, 114-129.

Gocke, C. (1928) Beitrage zur Druck festigkeit des Spongiosen Knochens. Beitr. Klin. Chir. 143, 539-566.

Goldstein, S. A., Wilson, D. L., Sonstegard, D. A. and Matthews, L. S. (1983) The mechanical properties of human tibial trabecular bone as a function of metaphyseal location. J. Biomechanics 16, 965-969.

Goldstein, S. A., Ku, J. L., Hollister, S., Kayner, D. C. and Matthews, L. S. (1986) The effects of applied stress on experimentally controlled remodeling in-trabecular bone. Transactions of the Orthopedic Research Society, p. 432.

Gong. J. K., Arnold. J. S and Cohn, S. H., (1964) Composition of trabecular and cortical bone. Anat. Res. 149, 325-332.

Halawa, M., Lee, A. J. C., Ling, R. S. M. and Vangala. S. S. (1978) The shear strength of trabecular bone from the femur and some factors affecting the shear strength of the cement-bone interface. Arch. Orthop. Traum. Surg. 92. $19-30$.

Hardinge, M. G. (1949) Determination of the strength of the cancellous bone in the head and neck of the femur. Surgery Gynec. Obstet. 89, 439-441.

Harrigan. T. P. and Mann, R. W. (1984) Characterization of microstructural anisotropy in orthotropic materials using a second rank tensor. J. Mater. Sci. 19, 761-767.

Hayes. W. C. and Carter, D. R. (1976) Postyield behavior of subchondral trabecular bone. J. Biomed. Mater. Res. S.m. 7, 537-544.

Hayes, W. C. and Snyder, B. (1981) Toward a quantitative formulation of Wolff's Law in trabecular bone in mechanical properties of bone. Americun Society of Mechanical Engineers AMD-45, 43-68.

Henshaw, R. M., Harrigan, T. P., Jasty, M., Mann, R. and Harris, W. H. (1986) Three dimensional map of trabecular architecture of the proximal and distal human femur and proximal human tibia. Transactions of the Orthopedic Research Society, p. 41.

Hvid, I. and Hansen. S. L. (1985) Trabecular bone strength patterns at the proximal tibial epiphysis. J. Orthop. Res. 3, 464-472.

Kaplan, S. J., Hayes, W. C., Stone, J. L. and Beaupre, G. S. (1985) Tensile strength of bovine trabecular bone. $J$. Biomechanics 18, 723-727.

Keller, T. S.. Hansson, T. H., Panjabi, M. M. and Spengler, D. M. (1987) Regional variations in the compressive properties of lumbar trabeculae. Transactions of the Orthopedic Research Society, p. 378.

Knese, K. H. (1956) Belastungsuntersuchungen des Oberschenkels unter der Annahme des Knochens. Morph. Jb. 97, 405-452.

Knese, K. H. (1958) Knochenstrucktur als Verbundbau Versuch einer Technischen Deutung der Materialstruktur des Knochens. Zwangslose Abhandlungen aus dem Gebiet der Normalen and Pathologischen Anatomie (Edited by Bergman, W. and Doerr, W.). Georg Tieme, Stuttgard.

Ku. J. L., Goldstein, S. A., Choi, K. W., London, M., Herzig. M. A. and Matthews. L. S. (1987) The mechanical properties of single trabecuale. Transactions of the Orthopedic Research Society p. 48.

Linde, F and Hvid, I. (1987) Stiffness behavior of trabecular bone specimens. J. Biomechanics 20, 83-89.

Lindahl, O. (1976) Mechanical properties of dried defatted spongy bone. Acta orthop. scand. 47, 11-19.

Martens, M., VanAudekercke, R., Delport, P., DeMeester, P. and Muelier, J. C. (1983) The mechanical characteristics of cancellous bone at the upper femoral region. $J$. Biomechanics 16, 971-983.

McElhaney, J. H., Fogle, J. L., Melvin, J. W., Haynes, R. R., Roberts, V. L. and Alem, N. M. (1970) Mechanical properties of cranial bone. J. Biomechanics, 3, 495-511.

Melvin, J. W., McElhaney, J. H. and Roberts, V. L. (1970) Development of a mechanical model of the human head. Determination of tissue properties and synthetic substitute materials. Soc. Automotive Engineers Trans. 79, 700-903.

Mente, P. L. and Lewis, J. L. (1987) Young's modulus of trabecular bone tissue. Transactions of the Orthopedic Research Society, p. 49.

Neil, J. L., Demas, T. C., Stone. J. L. and Hayes, W. C. (1983) Tensile and compression properties of vertebral trabecular bone. Transactions of the Orthopedic Research Society. p. 344.

Patel, M. R. (1969) The deformation and fracture of rigid cellular plastics under multiaxial stress. Ph.D. Thesis, University of California, Berkeley.

Pugh, J. W., Rose, R. M. and Radin, E. L. (1973) Elastic and viscoelastic properties of trabecular bone: dependence on structure. J. Biomechanics 6, 475-485.

Raux, P., Townsend, P. R., Meigel, R., Rose, R. M. and Radin, E. L. (1975) Trabecular architecture of the human patella. J. Biomechanics 8, 1-7. 
Ryan. S D. and Williams. J. L. (1986) Tensile testing of individual bovine trabeculae. Proceedings of the 12th Anmul Vortheast Bioenyineering Conference. (Edited by Orphanoudakis. S. C.) pp. 35-38, extended abstract.

Saha. S. and Gorman. P. H. (1981) Strength of human cancellous bone in shear and its relationship to bone mineral content. Transactions of the Orthopedic Research Society. p. 217.

Schoenfeld. C. M.. Lautenschlager. E. P. and Meyer. P. R.. Jr 119741 Mechanical properties of human cancellous bone in the femoral head. Med. Biol. Engng 12, 313-317.

Sonoda. T. 119621 Studies on the strength for compression. tension. and torsion of the human vertebral columns. $J$. Kyoto Pref. Med. Lnit. 71.659.

Stone. J. L.. Beaupre. G. and Hayes. W. C. (1983) Multiaxial strength characteristics of trabecular bone. J. Biomechunics $16.743-752$

Struhl. S.. Goidstein. S. A.. Dickie. D. L.. Flynn. M. J. and Matthews, L. S. (1987) The distribution of mechanical properties of trabecular bone within vertebral bodies and iliac crest: correlation with computed tomography density. Transactions of the Orthopedic Research Societ?. p. 262.

Townsend, P. R., Raux, P., Rose, R. M., Meigle, R. E. and Radin, E. L. (1975) The distribution and stiffiness of cancellous bone in the human patella. $J$. Biomechanics 8 . 363-367.

Weaver, J. K. and Chalmers. J. (1966) Cancellous bone: its strength and changes with aging and an evaluation of some methods for measuring its mineral content. J, Bone Ji Sury. 48., $289-29 \mathrm{~s}$

Williams. J. L. and Lewis. J. L. (1982) Properties and an anisotropic model of cancellous bone from the proximal tibial epiphysis. J. biomech. Engny 104. 50-56.

Woltf. J. (1892) Pas Destez der Transormation der Kinochen. Hirschwald. Berlin.

Yokoo, S. (1952) Compression test of the cancellous bone J. Kyoto Pref. Med. Unir. 51, 273. 